\title{
CORRELATION OF WATER ABSORPTION VALUES OF BITUMEN WATERPROOFING SHEETS OBTAINED ACCORDING TO CSN EN 14223 AND CSN 503602
}

The article deals with the issue of weight water absorption of bitumen waterproofing sheets. It compares two methodologies applicable to examination of water absorption of bitumen waterproofing sheets from the point of view of testing procedures. It compares the results of both the methods for individual bitumen sheets upon experimental measurement and examines mutual relation between the individual results. The experimental measurement was performed on bitumen sheets used for waterproofing of bridge deck [1].

Keywords: Bitumen waterproofing sheets (BWS), carrier, coarse gritting, fine gritting, water absorption.

\section{Introduction}

Water in liquid or gaseous state in bridge deck waterproofing system can be a source of a defect and consequent damage to the whole system of layers. It leads, e.g., to buckling of the carriageway that appears up to the carriageway surface course, see Fig. 1.

Apart from further numerous sources water may get into the waterproofing system even in the form of water contained in bitumen waterproofing sheets (BWSs). Water may penetrate into the BWS structure during manufacturing process, but also during storing before application. There are two test procedures dealing with water content in a complete BWS. An older one is presented in CSN 503602 [2] and a newer one in CSN EN 14223 [3]. General requirements for BWSs are presented in Table 1. Our aim is to define mutual dependence between the weight absorption set by the methodologies of CSN EN 14223 [3] a CSN 503602 [2] standards. At present we can still meet both the testing procedures and it is advantageous to know their mutual relation to be able to find quickly what values of weight absorption a particular BWS reaches. The term weight absorption is hereinafter referred to as absorption.

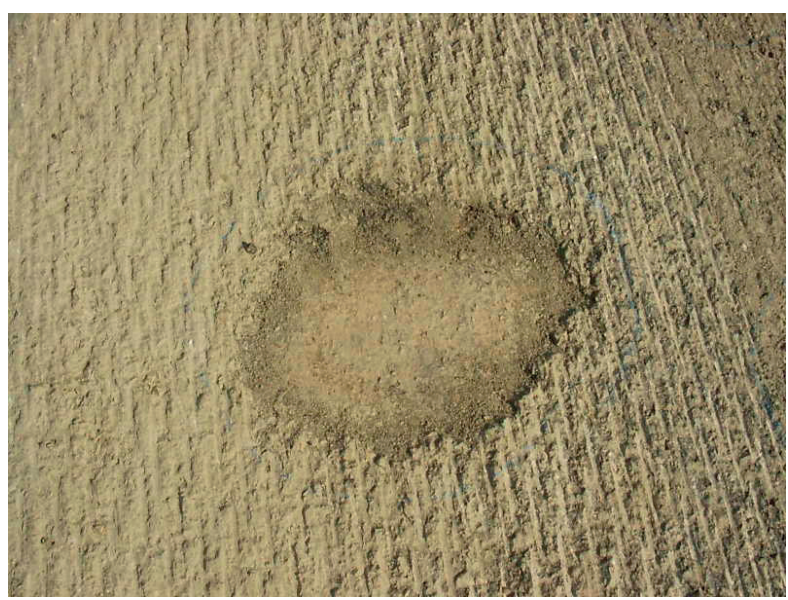

Fig. 1 Buckling under milled protective layer and surface course. Source: own

Quality requirements for bitumen waterproofing sheets as per [4], [5], [3] and [2]

\begin{tabular}{|c|c|c|c|c|}
\hline Requirement name & Size & Value & Testing method & Testing procedure applicability \\
\hline $\begin{array}{l}\text { Water absorption after } 28 \\
\text { days at } 23+3^{\circ} \mathrm{C}\end{array}$ & $\%$ & $\max .1 .5$ & $\begin{array}{l}\text { CSN 736242:2010 } \\
\text { CSN EN 14223 }\end{array}$ & Yes \\
\hline $\begin{array}{l}\text { Water absorption after } 30 \\
\text { days at } 20+2^{\circ} \mathrm{C}\end{array}$ & $\%$ & $\max .2^{*} .5$ & $\begin{array}{l}\text { CSN 736242:1995, } \\
\text { CSN } 50 \text { 3602:1967 }\end{array}$ & No \\
\hline
\end{tabular}

\footnotetext{
* Jan Plachy, Jana Vysoka, Radek Vejmelka, Zdenek Caha

Institute of Technology and Business in Ceske Budejovice, Czech Republic

E-mail: plachy@mail.vstecb.cz
} 


\section{Methodology and material}

20 BWSs used for single-layer application to waterproofing of concrete bridge decks in the Czech Republic and Slovakia were chosen for the testing in total. BWS used for waterproofing of bridges and roads on motorways and class 1 roads must belong to the waterproofing systems approved by the Ministry of Transport in the Czech Republic. In Slovakia approval of waterproofing system is directly subject to the particular investor after meeting legislation requirements.

The following group of BWSs is divided according to requirements of CSN 736242:2010 [4]. There are eleven BWSs with coarse gritting, five with fine gritting and four BWSs are without gritting. There are fifteen BWSs with plastomeric type substance and five with elastomeric type substance. The basic characteristics for the water absorption test are described in Table 2. All the BWSs had polyester carriers impregnated with bitumen substance.

Correlation is examined between two water absorption tests after 28 days according to CSN 736242:2010 [4], CSN EN 14223 [3] and for water absorption after 30 days according to CSN 736242:1995[5], CSN 503602 [2].

\subsection{Water absorption after 30 days}

Water absorption is determined by a testing procedure according to SN 503602 [2]. The testing specimen is immersed in water bath $(20 \pm 2)^{\circ} \mathrm{C}$ warm for 30 days. Three specimens of 100 $\mathrm{x} 100 \mathrm{~mm}$ are used for the test, see Fig. 2. Before immersion all loose gritting is removed by delicate wiping and the specimens are weighed with accuracy of $0.01 \mathrm{~g}$. The specimens are removed from the water bath after 24 hours and dried between sheets of filter paper $\left(80-100 \mathrm{~g} / \mathrm{m}^{2}\right)$ so as their surfaces are free of wet glossy stains and they are kept between the sheets. The testing specimens have to be weighed within 8 minutes from removal from the water at air temperature $20 \pm 2^{\circ} \mathrm{C}$ and relative humidity $60 \pm 5 \%$.

Water absorption of bitumen sheets is expressed as percentage, namely as the ratio of the difference of the weight of the testing specimen after immersion - the weight of the testing specimen before immersion to the weight of the testing specimen before immersion. BWS water absorption is the ratio of the weight difference to the weight of the testing specimen before immersion expressed as a percentage. The arithmetic average of five individual values is the test result.

Selected characteristics of the specimens. KEY: CG - Coarse gritting, FG - Fine gritting, N - geotextile surfacing (approx. 20g/ $\mathrm{m}^{2}$ ), PES - polyester fleece, P - plastomeric character, E - elastomeric character. Source: own.

\begin{tabular}{|c|c|c|c|c|c|c|c|c|c|c|}
\hline Specimen characteristics /specimen number & 2 & 3 & 6 & 7 & 8 & 9 & 10 & 11 & 12 & 13 \\
\hline Top surfacing & CG & $\mathrm{N}$ & $\mathrm{N}$ & FG & CG & FG & $\mathrm{CG}$ & CG & CG & CG \\
\hline Bitumen substance type & $\mathrm{P}$ & $\mathrm{P}$ & $\mathrm{P}$ & $\mathrm{E}$ & $\mathrm{P}$ & $\mathrm{P}$ & $\mathrm{P}$ & $\mathrm{P}$ & $P$ & $P$ \\
\hline Carrier - areal weight (g/m2) & 230 & 200 & 200 & 250 & 220 & 230 & 230 & 230 & 230 & 230 \\
\hline BWS thickness (mm) & 5.20 & 5.24 & 4.83 & 5.10 & 5.47 & 4.85 & 5.16 & 4.95 & 5.54 & 5.15 \\
\hline Place of BWS application (state) & SK & SK & SK & SK & SK & SK & $\mathrm{CZ}$ & $\mathrm{CZ}$ & $\mathrm{CZ}$ & $\mathrm{CZ}$ \\
\hline Specimen characteristics /specimen number & 14 & 15 & 16 & 17 & 18 & 19 & 20 & 21 & 22 & 25 \\
\hline Top surfacing & FG & $\mathrm{CG}$ & FG & CG & CG & $\mathrm{N}$ & FG & $\mathrm{N}$ & $\mathrm{CG}$ & CG \\
\hline Bitumen substance type & $P$ & $\mathrm{E}$ & $\mathrm{E}$ & $P$ & $\mathrm{E}$ & $P$ & $\mathrm{E}$ & $P$ & $P$ & $\mathrm{P}$ \\
\hline Carrier - areal weight $(\mathrm{g} / \mathrm{m} 2)$ & 230 & 230 & 230 & 230 & 250 & 250 & 250 & 250 & 250 & 280 \\
\hline BWS thickness (mm) & 6.25 & 5.46 & 4.80 & 5.67 & 5.05 & 4.15 & 4.15 & 4.06 & 5.22 & 5.18 \\
\hline Place of BWS application (state) & $\mathrm{CZ}$ & $\mathrm{CZ}$ & $\mathrm{CZ}$ & $\mathrm{CZ}$ & SK & $\mathrm{CZ}$ & $\mathrm{CZ}$ & $\mathrm{CZ}$ & SK & SK \\
\hline
\end{tabular}




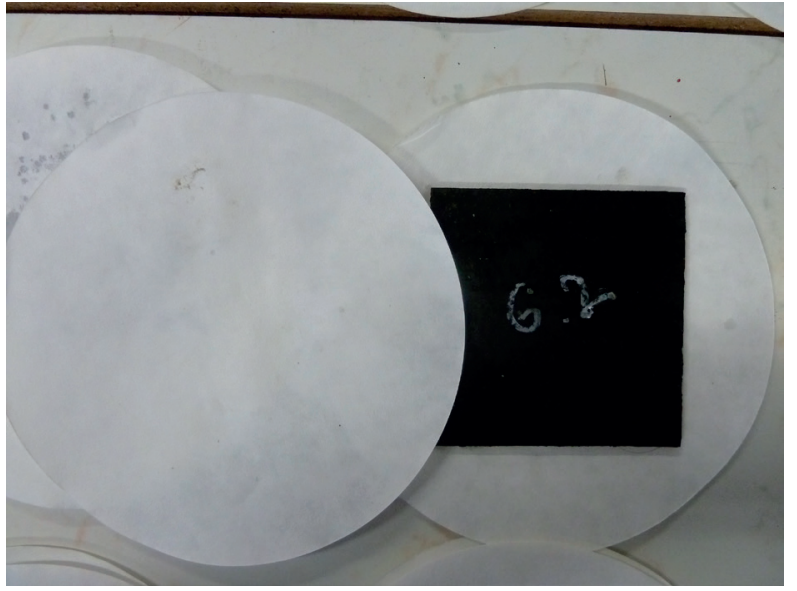

Fig. 2 Testing specimen between filter paper sheets for the water absorption test according to [2]. Source: own

\subsection{Water absorption after 28 days}

Water absorption is determined by a testing procedure according to CSN EN 14223 [3]. The testing specimen is immersed in water bath $(23 \pm 3){ }^{\circ} \mathrm{C}$ warm for 28 days \pm 4 hours, see Fig. 3. Weight is measured before and after immersion. Five test specimens $200 \times 200 \mathrm{~mm}$ are used for the test. All loose gritting has to be removed before weighing the test specimens and they are dried for $24 \mathrm{~h} \pm 30 \mathrm{~min}$. at temperature $(50 \pm 3){ }^{\circ} \mathrm{C}$. Then they are tempered for $1 \mathrm{~h} \pm 5 \mathrm{~min}$ at temperature $(23 \pm 3){ }^{\circ} \mathrm{C}$ and relative humidity $(50 \pm 5) \%$. After removal from water the specimens are dried in the air for $5 \mathrm{~h} \pm 5 \mathrm{~min}$ at temperature $(23 \pm$ $3)^{\circ} \mathrm{C}$ and relative humidity $(50 \pm 5) \%$. After expiry of this period they are weighed.

Water absorption of bitumen sheets is expressed as percentage, namely as the ratio of the difference of the weight of the testing specimen after immersion - the weight of the testing specimen before immersion to the weight of the testing specimen before immersion. BWS water absorption is the ratio of the weight difference to the weight of the testing specimen before immersion expressed as a percentage. The arithmetic average of five individual values is the test result

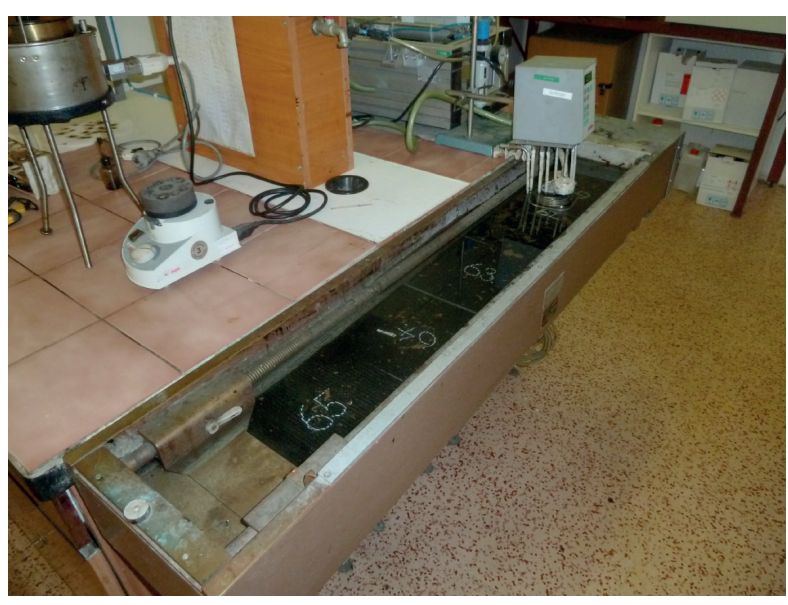

Fig. 3 Water bath according to [2], [3] for the specimens. Source: own

\subsection{Correlation of the testing procedures}

Our aim is to determine mutual dependence between the absorption values according to the mentioned standards. We expect existence of direct linear dependence or more precisely direct proportion between the two standards. First we are going to calculate the value of Pearson correlation coefficient, which is the most suitable for determination of linear dependence. After that we will perform a correlation coefficient test to confirm the statistical significance. Then we will prepare a linear regression model representing the relation between the two standards and perform a test of its significance and evaluate its suitability.

For comparison we will also perform a different method of examination of mutual dependence of the water absorption values according to both the standards. As the absorption values differ in different BWSs we will apply a straight line to the absorption values of the individual specimens in order of size for both the standards. We will get two straight lines this way, which we expect to be nearly parallel, and the relation between the two standards will then be given by mutual position of the straight lines.

\section{Test results}

\subsection{Water absorption after 28 and 30 days}

\begin{tabular}{|l|c|c|c|c|c|c|c|c|c|c|}
\hline Specimen characteristic /specimen number & 2 & 3 & 6 & 7 & 8 & 9 & 10 & 11 & 12 & 13 \\
\hline Absorption according to CSN 503602, 30 days in (\%) & 1.59 & 1.49 & 1.54 & 1.51 & 2.03 & 1.22 & 1.30 & 7.79 & 1.82 & 6.54 \\
\hline Absorption according to EN 14 223, 28 days in (\%) & 0.80 & 1.30 & 0.80 & 0.40 & 0.60 & 0.70 & 1.30 & 4.40 & 0.70 & 4.10 \\
\hline Specimen characteristic /specimen number & 14 & 15 & 16 & 17 & 18 & 19 & 20 & 21 & 22 & 25 \\
\hline Absorption according to CSN 503602, 30 days in (\%) & 0.94 & 2.71 & 0.84 & 1.55 & 1.05 & 1.79 & 0.95 & 1.28 & 1.76 & 1.30 \\
\hline Absorption according to EN 14 223, 28 days in (\%) & 0.40 & 1.60 & 0.40 & 0.60 & 0.20 & 0.50 & 0.50 & 0.80 & 0.90 & 1.30 \\
\hline
\end{tabular}




\subsection{Correlation of the testing procedures}

\subsubsection{Correlation coefficient and direct regression mode}

The value of Pearson correlation coefficient between standards CSN EN 14223 [3] and CSN 503602 [2] is $r=0.929$. The value of the testing statistics in the correlation coefficient test is $t=11.245$ at 20 degrees of freedom. P-value of the test is approximately $2.124 \cdot 10^{-10}$, one-side confidence interval at the level of $95 \%$ for the correlation coefficient is $(0.855 ; 1)$. The linear regression model expressing dependence of the absorption values according to CSN EN 14223 [3] on the values according to CSN 503602 [2] is CSN EN $14223=0.5785 \cdot$ CSN 503602.

Model determination coefficient $\mathrm{R}^{2}=0.86 \cdot 95 \%$ both side confidence interval for regression coefficient is $(0.4712 ; 0.6858)$.

\subsubsection{Method of two regression lines}

After performing the procedure described in 2.3 we got two straight lines with equations $y=0.182 x+0.131$ and $y=0.144 x-0.4$. The achieved results are graphically interpreted and described in Fig. 4.

\section{Discussion}

\subsection{Water absorption after 28 and 30 days}

The obtained absorption results, see Table 3, allow us to say that all the specimens except for two have met the requirements of the standards [2] a [3]. In the instance of the two specimens they were BWSs in which the carrier was insufficiently impregnated. BWSs with coarse gritting and with plastometric character had the highest absorption even in the case when the two above mentioned specimens had been removed from the examined group.

\subsection{Correlation of the testing procedures}

\subsubsection{Correlation coefficient and direct regression model}

The obtained value of the correlation coefficient between CSN EN 14223 [3] and CSN 503602 [1] is 0.929. This value shows strong direct linear dependence. This conclusion is also confirmed by the correlation coefficient test which confirms at the significance level of $5 \%$ that the correlation coefficient value is not zero. The interval estimation then shows that this value is with $95 \%$ liability higher than 0.855 . The created regression model of

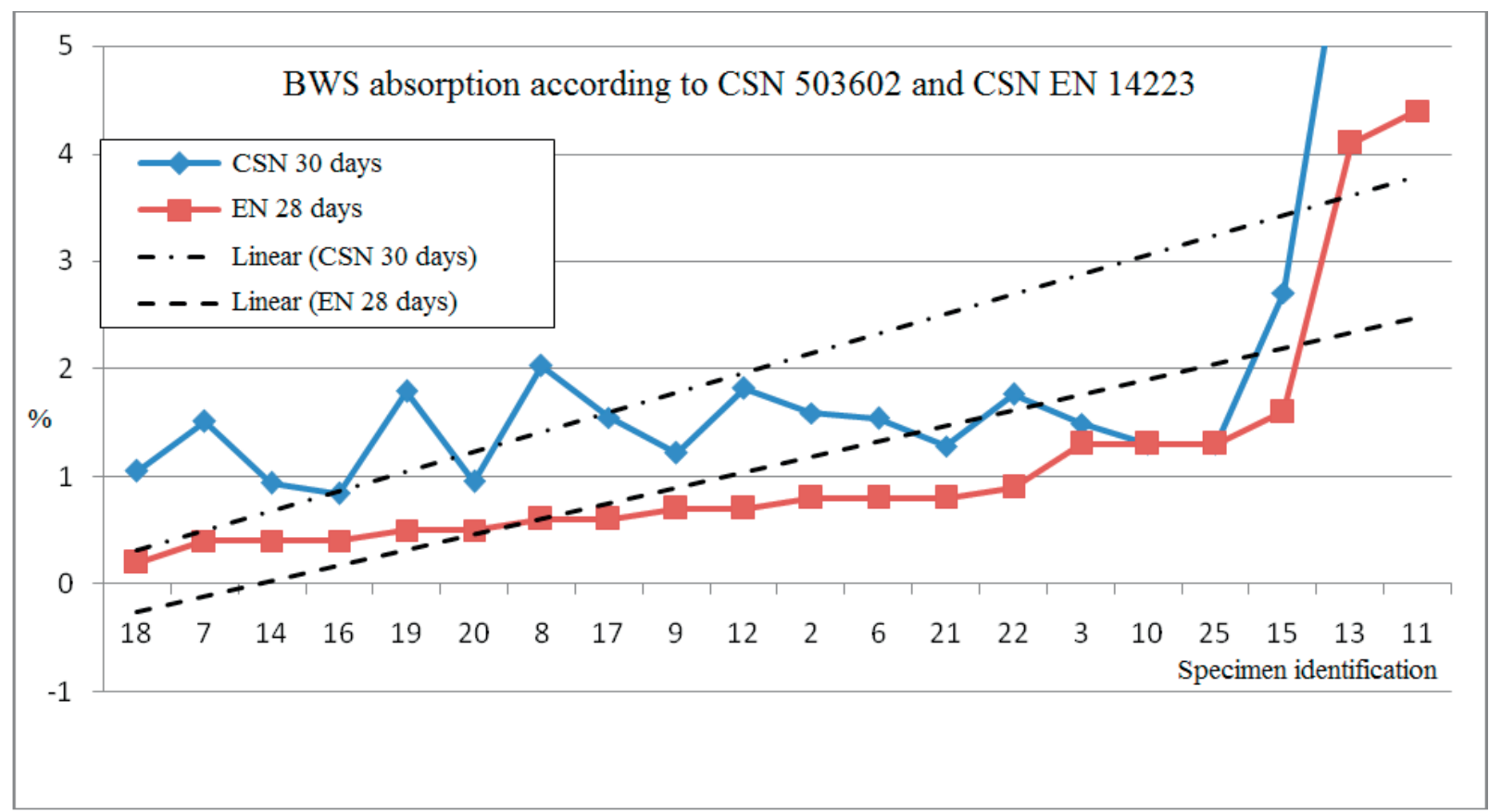

Fig. 4 Results of the BWS weight absorption test according to [2] and [3]. Source: own 
dependence of absorption values according to CSN EN 14223 [3] on the values of CSN 503602 [2] is statistically significant and the determination coefficient whose value approximates to $90 \%$ shows that suitability of this direct proportion model has been confirmed as the absolute member of the equation of the line is statistically insignificant so it can be considered zero.

\subsubsection{Method of two regression lines}

The hypothesis set in 2.3 was confirmed even by the second approach. The directions of both the regression lines are very close so they can be considered approximately parallel with the given range. Their distance is then given by the absolute value of the difference of the absolute members of the lines and it is 0.531 , while this value falls into the interval estimation of the regression coefficient determined by the previous procedure.

\section{Conclusion}

We have managed to derive the mutual relation between the values of the examined data files by means of two different approaches. Both the methods led to the conclusion that this relation can be considered direct proportion, which corresponds with the original assumptions.

\section{References}

[1] CSN EN 14695:2010. Flexible Sheets for Waterproofing - Reinforced Bitumen Sheets for Waterproofing of Concrete Bridge Decks and other Trafficked Areas of Concrete - Definitions and Characteristics. Prague : Czech Standards Institution. 2010-05-01. Classification mark 727605.

[2] CSN 503602:1967. Testing Roofing and Waterproofing Materials in Roles. Prague : Czech Standards Institution. 2010-02-22. Classification mark 503602.

[3] CSN EN 14223:2006 Flexible Sheets for Waterproofing - Reinforced Bitumen Sheets for Waterproofing of Concrete Bridge Decks and other Trafficked Areas of Concrete - Determination of Water Absorption. $1^{\text {st }}$ ed., Prague : Czech Standards Institution, $2006-07-01$. Classification mark 727677.

[4] CSN 736242:2010. Design and Construction of Pavements on Road Bridges. Prague : Czech Standards Institution. 2010-04-01. Classification mark 736242 .

[5] CSN 736242:1995. Design and Construction of Pavements on Bridges and Roads. Prague : Czech Standards Institution. 1995-03-01. Classification mark 736242. 